\title{
CONCEPTUAL VARIATIONS ON READING COMPREHENSION THROUGH HIGHER ORDER THINKING SKILLS (HOTS) STRATEGY
}

\author{
Nani Ronsani Thamrin \\ English Education Department, Faculty of Teacher Training and Education, Universitas Kuningan, Indonesia \\ E-mail: nanironsani.thamrin@gmail.com \\ Silvia Agustin \\ English Education Department, Faculty of Teacher Training and Education, Universitas Kuningan, Indonesia \\ E-mail: silvia.nitsuga@gmail.com
}

APA Citation: Thamrin, N. R., \& Agustin, S. (2019). Conceptual variations on reading comprehension through higher order thinking skills (HOTS) strategy. English Review: Journal of English Education, 7(2), 93-100. doi: 10.25134/erjee.v7i2.1777.

Received: 22-01-2019

Accepted: 16-04-2019

Published: 01-06-2019

\begin{abstract}
Thinking capability is the most significant aspect in educational process. As every student has his own distinctive method of thinking, he will then possess his learning concepts. Being a critical thinker means they have to be able to think more critical than any other people, by practicing their skills through comprehending the material and the content of the text. Therefore, this paper discusses the phenomenon of conceptual variations on reading comprehension through Higher Order Thinking Skill (HOTS) strategy in Universitas Kuningan and describes how the HOTS strategy improves the students' skills in comprehending the academic reading text. The data collected from a classroom observation and interview were analyzed qualitatively by using categories formulated based on theories related to HOTS strategy. As a result, it was found that various concepts on reading comprehension are seen from the C1-C6 phase of HOTS strategy and critical reading. This indicates that most students have higher order thinking skills in comprehending the text in critical reading class. Finally, the findings are expected to be references for English teachers in implementing various teaching strategy.
\end{abstract}

Keywords: critical reading; higher order thinking skills; reading comprehension.

\section{INTRODUCTION}

The need of learning reading is increasing along with the needs of students to acquire information during their study. The mutual relationship between students' academic reading skills and educational achievements involves the four basic skills. These include reading, writing, critical thinking, oral presentation, and media literacy, which involve receptive and productive skills of students (Tinto in Hermida, 2009).

As receptive skill, reading becomes the most necessary skill to get information for students since the reading courses which are explained by teachers in classroom is not enough. There are benefits of teaching reading that provide good models for English writing (Harmer, 2007). However, to teach this skill, teachers need to improve methods instead of LOTS (Lower Order Thinking Skill) to enhance students thinking skills. Anderson and Krathwohl (2001) categorized level of reading and cognitive development into six level and changed the terms from LOTS to HOTS which is started with remembering, understanding, applying, analyzing, evaluating, and creating.
The implementation of HOTS in classroom would be beneficial for both students and teachers as well. This research proposed the description of students' conceptual variations on reading comprehension through HOTS strategy as well as the improvements of the skills in comprehending the academic reading text using HOTS strategy. This research also deals with critical reading (Cotrell, 2005), the steps of HOTS strategy (Anderson \& Krathwohl, 2001), and the concepts related to HOTS.

HOTS strategies usually required for those who want to develop their thinking skills. Therefore, good readers need higher order thinking strategies to think of, and direct their perception before, during and after reading the passages. Beneath all, students need to acquire the HOTS strategy to improve their abilities in thinking process instead of thinking simply of the passage they read. Upon even strategies of HOTS, here is a detail information on how the strategies of HOTS is applied according to Seif (2012).

First, giving high questions during reading activity. Giving questions is defined by 
Hendricks et al. in Seif (2012) as a strategy in order to help students to improve their reading skills to deeper thinking and learning for grasping the content of the text. Thus, teachers should give higher-order questions related to the text during reading activities in the classroom. The questions are prepared by the teachers and given to the students during the reading activity by stopping at intervals and proposing the questions directly to the students. This activity is in line with the theory of directed reading proposed by Haggard in Seif (2012) that questioning can be facilitated with the Directed Reading-Thinking Activities Approach (DRTA). This strategy is believed as a way on how to improve students' thinking skills in reading activity. As supported by Raphael in Seif (2012) that "a Question-Answer Relationship (QAR) technique has been linked to improve students' reading comprehension after reading."

Second, making inference related to reading between lines strongly. Students could be trained to utilize the illustrations, graphs, and headline from the text to create inferences. Generating conclusion is closely to the description of making inference. According to Doff in Seif (2012), we can engage our experience to the reading passage based on our experience, otherwise we can imagine ourselves being on the stories that serve much experience, so that we can feel and grasp the meaning that author's mean from the text.

Third, teachers take very important role in every single program of education. Seif (2012) stated that teachers expose the student to be more aware of the material they learn from the very first place, should not talk too much, improve certain strategies to cultivate thinking behavior, use media, ask question regularly, and break the classroom into the small groups to work on the more specific task. Therefore, this is perhaps an effective way to train students to think without noticing it. Cotton in Seif (2012) suggests that teachers need to utilize various instructional approaches to develop thinking skills and to enhance students' knowledge and thinking skills by using generating questions, redirection and reinforcement in order to achieve the goal. Besides, the questions proposed by the teachers must be higher-order questions and of course teachers need to be patient to wait to the students' responses.

Furthermore, Anderson and Krathwohl (2001) developed the Bloom's taxonomy of cognitive objectives by categorizing it into six phase, starting from $\mathrm{C} 1$ to C6 - Remembering, Understanding, Applying, Analyzing, Evaluating and Creating. The name of these six major categories were changed from noun to verb forms. As the taxonomy reflects different forms of thinking of every individual regarding the problems they have. Besides, thinking is an active process so that verbs are used rather than nouns. This is one of the reason why Anderson made an adjustment to Bloom's taxonomy terms. Figure 1 describes the change of the Bloom's taxonomy into Anderson's.

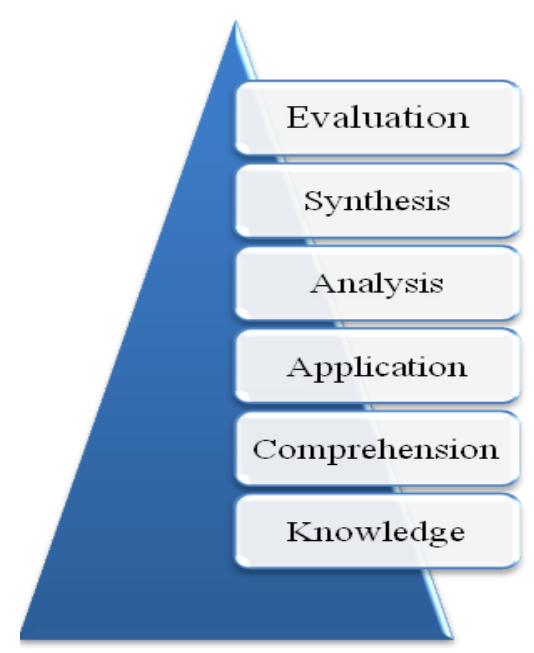

Bloom's Taxonomy

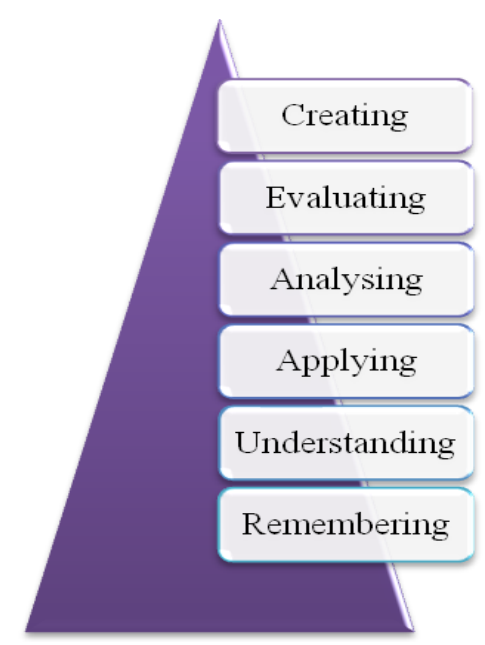

Anderson' Taxonomy

Figure 1. The comparison of Bloom 's taxonomy and Anderson's taxonomy 
The $\mathrm{C} 1$ phase, remembering, includes recalling information, recognizing, listing, describing, retrieving, naming and finding which all belong to the input process (receptive skills). The students commit this phase in the first time they get information by listening or reading.

After they have been exceeded the $\mathrm{C} 1$ phase, they go through the next phase, C2, understanding. This phase presents the process of explaining ideas or concepts, interpreting, summarizing, paraphrasing, classifying and explaining the content of the information.

C3, applying, represents the using of information in another familiar situation. It includes implementing, carrying out, using, and executing the information got in any other particular situation and conditions in appropriate ways.

C4, analyzing, is going to break the information into parts to explore their understandings and the relationships of the information they received. This phase includes comparing, organizing, deconstructing, interrogating, and finding.

C5, evaluating, reviews the justification of decision or course of an action. It includes checking, hypothesizing, critiquing, experimenting, and judging every information they received from any sources.

Finally, C6, creating, is the process of generating new ideas, products, or ways of view things. It includes designing, constructing, planning, producing, and inventing.

The phase of $\mathrm{C} 1$ to $\mathrm{C} 3$ belong to Lower Order Thinking Skills, meanwhile the rest, C4 to C6 is Higher Order Thinking Skills. In short, the main purpose of HOTS is that the students are able to collect the information, categorize it, and generating new ideas to be implemented in any other situations they have, beyond the classroom or any other occasions.

\section{METHOD}

This study intends to find out students' conceptual variation and to describe the improvements of students' skills in reading comprehension through HOTS strategy in critical reading. It is largely qualitative descriptive meaning that this study is fully describing the phenomenon that happened in the classroom. This study was conducted in a critical reading class in Universitas Kuningan. Two class of fourth semester students were involved in this study. 28 students in class A consists of 8 male students and 20 female students; they are in range of 18-25 years old. Meanwhile, 27 students in class B consists of 9 male students and 18 female students; they are also in range of 18-25 years old. The students were selected since they have taken reading subject in the previous semester. Thus, the students have known the basic knowledge about being a good reader and the function of reading activity along their study as well.

The data collected by applying a classroom observation and interview were then analyzed qualitatively by using categories formulated based on theories related to HOTS strategy. There are 8-10 meetings observed and 37 students were interviewed by using Burke's reading interviews' guidelines (2005), Ifanc and Wales (2010), and Burns, Maki, and Karrich (2013). The interview guidelines depict the information on how students' behavior in reading the passages and how they comprehend the content as well as how they implement higher order thinking skills on reading comprehension in Critical reading class.

In assessing student's capability in Higher Order Thinking, the researcher uses the indicator of assessment adapted from Lewy and Aisyah (2011) as presented in Table 1.

Table 1. Categories for assessing higher order thinking skills

\begin{tabular}{cc}
\hline Student's mark & $\begin{array}{c}\text { Level of students' higher order } \\
\text { thinking }\end{array}$ \\
\hline $100-76$ & Excellent \\
$75-51$ & Good \\
$50-26$ & Enough \\
$25-1$ & Poor \\
\hline
\end{tabular}

(adapted from Lewy \& Aisyah, 2011)

The level of students' higher order thinking is categorized by the result of the test conducted during the mid-term and final exam. The researcher has got the permission from the lecturer to take the result of the test to be the standards of determining students' HOTS.

In analyzing the data, the researcher uses steps of analyzing qualitative data proposed by Yin 
(2011) which include; Compiling: the researcher sorts the collected data from observation, interview and filed-notes; Disassembling: the researcher breaks the data into more specific or smaller pieces. In this case, the research tries to classify the data into several aspects of HOTS level and critical reading skills; Reassembling: the researcher depicts the data and serves it into graphic or tabular forms; Interpreting: the researcher describes the collected data and analyzed it by using her own interpretation and assumption supported by theories; and Concluding: the research concludes the result of the research which is proven by the data and theories.

\section{RESULTS AND DISCUSSION}

From the observation, it is found that the lecturer has already implemented the HOTS strategy in critical reading class and made the students have the conceptual variation on reading comprehension. There are two types of major cases of the students along the learning activities in the classroom, they are the steps related to the critical reading and the concepts related to the HOTS. These two major cases involve the HOTS implementation in order to create good atmosphere and to achieve the learning goal effectively.

\section{Students' conceptual variation of reading comprehension}

Based on the observation and interview, it is found that students were able to apply the HOTS strategy in their critical reading activities in the classroom. Students' conceptual variation can be seen in the following.

\section{The critical reading}

Applying critical thinking in reading activity is a very important aspect to develop the students' capability in catching the sense of the text. Critical reading is not the same as the other kinds of reading, like skimming or scanning the text, but rather using the higher thinking skills. This is the useful strategy to the information placement and enhance a general feel of the subject. Anyhow, it is usually found in narrower reading material. Critical reading, as Cotrell (2005) stated, "requires the students to focus their attention much more closely on certain parts of a written text, holding other information in mind". Thus, it is obvious that the students need to pay more attention and focus on what their reading order to get the meaning of the context of the reading passage by holding the information. It not only relies on the students' reading capability, but also involves the analysis, reflection, evaluation and making judgements (Cotrell 2005). It means that the students are expected to be able to analyze the text, reflect it to their life, evaluate and make judgement based on their opinion and life experiences which need higher order thinking skills.

The implementation of HOTS strategy can be proved since the lecturer conducted some prominent characteristics of critical reading in her teaching activities. Those were in the first activity on March $13^{\text {th }}, 2018$ at $01.00-02.30$ p.m. to the last meeting on May $15^{\text {th }}, 2018$.

First, the student can predict what the text was about and also gave their logical reason although the prediction was not the same as the content of the text and reconnect it with their prior knowledge and previous experiences which help them in making prediction. It is in line with Rauch et al. (1968) in Seif (2012) who stated that prerequisite knowledge or prior knowledge would be helpful for someone to get started to read the text; conversely he would get some trouble along the reading activity, such as being confused and strange.

The difference of prediction and the content of the text was also shown in following interview script.

Interviewer : Now, we're beginning to the predicting, summarizing, etc. For prediction, do you ever try to predict of what will the text talk about before you read the text?

Student 3 : I am more likely to the story, for example emmmm the Disney story was all about the happy ending right? If the Disney, the middle of the story was like this, for example, so the ending must be happy ending. So, the prediction about the film was not really far from that, that will be happy ending. But, not all of them like that nowadays."

However, the different prediction and the content of the text was shown in different class in which the meeting was conducted on Tuesday, March $20^{\text {th }}, 2018$ at 01.00-02.30 p.m. The text was about the Chitchen Itza, a historical place in Mexico which was taken from the Internet. The student predicted that the place was in ASEAN country, but it is located in Mexico. They also found some difficult words and it became a barrier to them in grasp the content of the text, such as the word of "settlement", "tribes" \& "sculpture". They need more time to understand the content of the text as well as to identify the 
text because they need to find the meaning of those difficult vocabularies.

Second, the students used their skills in constructing meaning from instructional messages, including oral, written, and graphic communication (C2-phase 2) and applying a procedure to a familiar task (C3-phase 3 ) by summarizing the text and retell it to their friends in the classroom in two or three sentences.

The article about developing tourism spot in Jogjakarta was taken from Jakarta post entitled "Four Destinations in Yogyakarta to be Revamped", posted on Sunday, March 25th 2018 at 08:01 a.m. Here, the students presented to their friends that "Indonesian have to develop and increase the number of the tourists to visit the other spot in Jogjakarta, beside Borobudur temple as the popular icon, so that Indonesia can promote its natural tourism sites that spread in all of the region."

Most of the students could summarize the content of the text and retell their summary to their friends in two or three sentences. This is shown in the following interview script.

\section{Interviewer: Could you re-explain to your friends about what have you read? \\ Student 1 : It depends on the text, if it is easy to understand so I can do it. \\ Interviewer : For example? \\ Student 1 : Ya, for example the news that I have knew before. So, because I understood, I can directly retell the news to my friends. But, if the news was unfamiliar, I don't dare to do so. \\ Interviewer: If you are asked to re-explain the text in one or two sentences, could you do that?}

Student 1 : InsyaAllah I can.

The illustration is in line with the purpose of the critical reading through HOTS strategy that is to improve students' skills to conclude the text using their own words and perceptions. According to Anderson and Krathwohl (2001), after exceeding the $\mathrm{C} 1$ phase, students go through the next phase, $\mathrm{C} 2$, understanding. This phase presents the process of explaining ideas or concepts, interpreting, summarizing, paraphrasing, classifying and explaining the content of the information.

Third, the students tend to generate questions by asking themselves about $5 \mathrm{~W} 1 \mathrm{H}$ related to the text they have. In generating question, the students are asking themselves why something is happened during their reading activity. They explore the reason why anything happened or how the events are happened in the story by putting their prediction and anything they knew beyond the text, such as experiences and ideas to the text.

"Yes, of course. For example, what was the text talking about. The 5W1H question must be used, because the question was all about the $5 \mathrm{WlH}$. What is the content of the text, we should be able to explain it, we have to know where the case is happened." (Student 8)

The illustration represents the theory of Anderson and Krathwohl (2001) who stated that in C3, applying, represents the using of information in another familiar situation. It includes implementing, carrying out, using, and executing the information got in any other particular situation and conditions in appropriate ways. Besides, $\mathrm{C} 4$, analyzing, is going to break the information into parts to explore their understandings and the relationships of the information they received. This phase includes comparing, organizing, deconstructing, interrogating, and finding.

On the other hand, generating question by asking themselves is happening as the result of the curiosity as depicted in the following script.

Interviewer: Now we're going to the generating question. When you are reading, do you ever ask yourself, who is planning this kind of action, for example, or why this is happened?

Student 11 : Sometimes, yes. If I saw an accident for example, so I am asking myself who is that? why this is happened? Just like want to know, just feel curious.

Fourth, the students use quotation and evidence based on the paragraph of the text to answer their generating questions. For example, in class meeting on Tuesday, May $8^{\text {th }}, 2018$ at 02.08-03.30 p.m., the students clarify their answer by giving proof based on the text where the statement were supported by the evidence in the text and quotations. This is in line with the $5^{\text {th }}$ phase proposed by Anderson and Krathwohl (2001) who stated that C5, evaluating, reviews the justification of decision or course of an action. It includes checking, hypothesizing, critiquing, experimenting, and judging every information they received from any sources. It means that the students are evaluating their ideas and thoughts by finding supporting information. 


\section{Students' ways of thinking}

The first concept related to HOTS is procedural knowledge which means how to do something, manners of investigations and the standard for utilizing abilities, algorithms, techniques, and methods (Pickard in Seif, 2012). It emerges as a type of knowledge and a prerequisite for higher order thinking since it includes manners of investigations and utilization of the abilities based on the standards. In addition, the capability to presents a numbers of rules and provisions is called as "information learning"; meanwhile the capability to implementing a numbers of rules and provisions in a single collection is called as "application". HOTS is usually perceived as the procedural knowledge.

For instance, on Tuesday, March 13 ${ }^{\text {th }}, 2018$ at 09.30-11.00 a.m., the students were asked by the lecturer to analyze the organizational structure of the text which includes definition, classification, examples, comparison, summarization, time order, elaboration, contrast and illustration. They were capable to analyze the text following the procedure given by the lecturer. Besides, they present the result of their analysis to their friends.
Interviewer : First question, if you read something, did you get any useful information for your own?

Student 8 : Of course. There must be a useful information in the text. For example, in the magazine and in Kuningan news. There is a lot of information about the weather in the area of Kuningan.

From the script, we can conclude that the procedural knowledge is not only used for presenting the result of our perception to the other people, but also to inform others about alternative solution or any other information that might be useful. Every information from the text are useful, otherwise they did not apply it to their daily life. As quoted from the interview, the information in the text might be useful for everyone, but not all can be applied. It depends on the condition and situation which require the information to be applied.

The second concept is Comprehension which is a part of Bloom's taxonomy. It is deemed to be one of the lower order thinking skills and integrated to the HOTS foster. Although it is such an important component, it does not belong to Higher order thinking skills. The new "schemata" and information is created from the individual's comprehensions using particular activities (Crowl in Seif, 2012), including, but not limited to, arousing and answering questions that prosecute higher order thinking about effete and recent ideas, encountering contradictory ideas and information, problems, or dilemmas, exploring and making discoveries, conducting systematic inquiries, summarizing, reciting, and discussing new ideas and their relationships, relating new understandings to other concepts, applying new ideas and information in basic problem-solving activities, or reflecting and verbalizing about cognitive processes involved in comprehension.

Instead of perceiving the meaning of a difficult word in a text, they tend to ignore the difficult words or vocabulary as presented in the following script.

Interviewer: For example, when you are reading then suddenly you found difficult vocabulary, but actually you know that it belongs to which class-word. Is that helping you to understand the content of the text?

Student 15 : To be honest, if I found difficult word, I just ignore it. I don't care. But yeah, we can use our logic.

The last concepts related to the HOTS is creativity and intelligence. Students' creativity and intelligence can be seen on how they could give alternative solution for every single problem or case they found on the text. The solution was not only seen in a single point of view, but also in various point of views.

Naturally, the creativities do not belong to higher order thinking resolutely. It has a strong relationship with the process. The concepts and principles need to be solved by arousing new ideas and a good problem solving. It took an important role in higher order thinking process as Pasteur observes that "chance favors only the prepared mind" because "only a trained mind can make connection between unrelated events, recognize meaning in a serendipitous event, and produce a solution that is both novel and suitable" (Crowl cited in Seif, 2012).

Meanwhile, the meaning of intelligent is not merely about the capability to mean something. It concerns to seven kinds of intelligences or the natural capability of human. It includes linguistic-verbal, logical-mathematical, spatial, musical, bodily-kinesthetic, interpersonal and intrapersonal abilities. Every student has several intelligences which differs them from one to another. Exercises, learning and experiences are the things that may help individual to foster their abilities substantively. In this point of view, Gardner in Seif (2012) declares that every 
individual is "capable to fostering their intelligence and some particular intelligence might be more developed than any other intelligence". Likewise, every individual can arouse their intelligence by education, particularly the moment when they start to train their intelligence at the early ages.

For example, in the class meeting on Monday, April $16^{\text {th }}, 2018$ at $11.00-12.30$ a.m., there were students who bring an article entitled "10 die, dozens hospitalized after drinking bootleg liquor" posted on Tuesday, April 3rd 2018 at 07.02 p.m. at Jakarta Post. The lecturer asked them for the solution in three point of views, including from the government's point of view, the seller's point of view and the last from the parents' point of view. Automatically, the students answered that question by saying:

"the things that should be done by the government is that conducting the preventive action and regulation on how people can consume the alcoholic drinks. For the seller, it would be better if they do some more positive business rather than selling the alcoholic drinks. For the parents, they should pay more attention in watching their children in case they do negative things, so this kind of case would be never happened again in the future." (researcher's note)

Students' improvements in comprehending academic reading text through HOTS strategy From the analysis towards the interview and observation data, the researcher found some tendencies of the students which show the improvements from LOTS to HOTS in critical reading comprehension.

First, the students could actively retrieve knowledge from their long-term memory (C1phase 1) by predicting the text talks about, by analyzing the picture, headline and supporting ideas, as well as by involving their prior knowledge and their previous experience. In this case, Anderson (2001) stated that the $\mathrm{C} 1$ phase, remembering, includes recalling information, recognizing, listing, describing, retrieving, naming and finding which all belong to the input process (receptive skills). The students commit this phase in the first time they get information by listening or reading.

Second, the students used their skills in constructing meaning from instructional messages, including oral, written, and graphic communication (C2-phase 2) and applying a procedure to a familiar task (C3-phase 3) by summarizing the text and retell it to their friends in the classroom in two or three sentences.
Third, the students were able to break the reading material into its constituent parts and determine how the parts relate to one another and to overall structure or purpose (C4-phase 4 ) by analyzing and grasping the content of the text. Here, the students tend to generate questions by asking themselves about $5 \mathrm{~W} 1 \mathrm{H}$ related to the text they have.

Lastly, the students were able to detect inconsistencies or fallacies within a process or product; determine whether a process or product has internal consistency; detect the effectiveness of a procedure as it is being implemented (C5Phase 5); put elements together to form a coherent or functional whole; and reorganize elements into a new pattern or structure (C6Phase 6) by creating alternative solution for every single problem they found on the text they read.

\section{CONCLUSION}

Based on the analysis, the researcher can draw conclusions as follows. There were two major types of conceptual variation in reading comprehension through HOTS strategy in critical reading class which involved the steps of HOTS strategy (remembering, understanding, applying, analyzing, evaluating and creating) and critical reading (predicting, summarizing, generating question and clarifying). The students tend to begin to involve their prior knowledge, experience, and logical reason after they had known about the steps of critical reading and HOTS strategy delivered by the lecturer during the classroom activities. In this case, the students were classified as the LOTS and HOTS students based on the consideration of how much the students involved their critical thinking in responding to the text that given by the lecturer.

\section{REFERENCES}

Anderson, L., \& Krathwohl, D. (2001). A taxonomy for learning, teaching and assessing: A revision of bloom's taxonomy. New York: Longman Publishing.

Burns, M. K., Maki, K. E., \& Karrich, A.C. (2013). Using performance feedback to increase reading comprehension strategy use. Minnesota: University of Minnesota.

Cotrell, S. (2005). Critical thinking skill: Developing effective analysis and argument. New York: Palgrave Macmillan.

Harmer, J. (2007). How to teach English. England: Pearson Education.

Hermida, J. (2009). The importance of teaching academic reading skills in first year university 
Nani Ronsani Thamrin \& Silvia Agustin

Conceptual variations on reading comprehension through higher order thinking skills (HOTS) strategy

courses. The International Journal Research and Review, 3, 21-31.

Ifanc, C., \& Wales, Y. (2010). Guidance on the teaching of higher-order reading skills: INSET opportunities for teachers of all subjects across the curriculum at key stages 2 and 3. UK: Crown.

Lewy, Z., \& Aisyah, N. (2011). Pengembangan soal untuk mengukur kemampuan berpikir tingkat tinggi pokok bahasan barisan dan deret bilangan di kelas IX Akselerasi SMP Xaverius Maria Palembang. Jurnal Pendidikan Matematika, 3(2), 14-28.
Seif, A. (2012). Evaluating higher order thinking skills in reading exercises of English for Palestine Grade 8. Disertation. Gaza, The Islamic Universities.

Yin, R. K. (2011). Qualitative research from start to finish. New York: Guildford Press. 